\section{Thyroid Hormone Stimulation of Phosphatidylcholine Synthesis in Cultured Fetal Rabbit Lung}

Philip L. Ballard, M. Leslie Hovey, and Linda K. Gonzales Department of Pediatrics and Cardiovascular Research Institute, University of California, San Francisco, California 94143 bstract. To investigate the mechanism of thyroid hormone action on pulmonary surfactant synthesis, we characterized the effect of triiodothyronine on phosphatidylcholine synthesis in cultured fetal rabbit lung. Since glucocorticoids stimulate surfactant synthesis and reduce the incidence of Respiratory Distress Syndrome in premature infants, we also examined the interaction of triiodothyronine and dexamethasone.

The rate of choline incorporation into phosphatidylcholine was determined in organ cultures of rabbit lung maintained in serum-free Waymouth's medium. In 23-d lung cultured for $72 \mathrm{~h}$, the increase in choline incorporation with triiodothyronine alone, dexamethasone alone, and triiodothyronine plus dexamethasone was 50,62 , and $161 \%$, respectively. Both triiodothyronine and dexamethasone also increased incorporation rates with glucose, glycerol, and acetate as precursors, and stimulation with triiodothyronine plus dexamethasone was at least additive. Dexamethasone, but not triiodothyronine, affected distribution of radioactivity from $\left[{ }^{3} \mathrm{H}\right]$ acetate among phospholipids. Stimulation was first detected 8-12 h after addition of triiodothyronine, and then increased in a linear fashion. With triiodothyronine plus dexamethasone, stimulation was maximal at 48$72 \mathrm{~h}$, and was supra-additive at all times. Exposure of cultured lung to dexamethasone enhanced the subsequent response to triiodothyronine, but not vice versa. When triiodothyronine was removed from cultures, there was

This work was presented in part at the 1983 meetings of American Pediatric Society and Society for Pediatric Research, Washington, DC, and has been published in abstract form in Pediatr. Res. 17:31A.

Address all correspondence to Dr. Ballard, University of California at San Francisco, CVRI/1315-M, San Francisco, CA 94143.

Received for publication 23 January 1984 and in revised form 17 May 1984.

J. Clin. Invest.

(c) The American Society for Clinical Investigation, Inc.

0021-9738/84/09/0898/08 $\$ 1.00$

Volume 74, September 1984, 898-905 no further stimulation and the triiodothyronine effect was partially reversed within $24 \mathrm{~h}$. Half-maximal stimulation of choline incorporation occurred at a triiodothyronine concentration $(0.10 \mathrm{nM})$ very similar to the dissociation constant for triiodothyronine binding to nuclear receptor $(0.11 \mathrm{nM})$. The relative potencies of thyroid hormone analogs for nuclear binding and stimulation of phosphatidylcholine synthesis were also similar: triiodothyroacetic acid > triiodothyronine-proprionic acid $>$ L-triiodothyronine $\sim$ D-triiodothyronine $\gg$ thyroxine $\gg$ 3,5-diethyl-3'-isopropyl-DL-thyronine $\sim 3,5$ dimethyl-3'-isopropyl-L-thyronine $\sim$ reverse triiodothyronine. The effect of triiodothyronine was blocked by the presence of either actinomycin D or cycloheximide, inhibitors of ribonucleic acid and protein synthesis, respectively.

We conclude that triiodothyronine stimulates phosphatidylcholine synthesis by a process involving nuclear receptors and de novo ribonucleic acid and protein synthesis. These findings support the concept that endogenous triiodothyronine has a physiologic role in lung maturation and suggest that combined antenatal therapy with thyroid hormone and glucocorticoid may be useful for prevention of Respiratory Distress Syndrome in the premature infant.

\section{Introduction}

Adequate development of the pulmonary surfactant system is required for normal respiration at birth. Surfactant is a complex mixture of lipids and proteins characterized by a high content of saturated phosphatidylcholine (PC) ${ }^{1}$, which lowers the surface tension in alveoli and thereby prevents atelectasis. A deficiency of surfactant in premature infants is the major cause of neonatal Respiratory Distress Syndrome (RDS).

1. Abbreviations used in this paper: Dex, dexamethasone; DIET, 3,5'diethyl-3'-isopropyl-DL-thyronine; DIMIT, 3,5-dimethyl-3'-isopropyl-Lthyronine; PC, phosphatidylcholine; RDS, Respiratory Distress Syndrome; TRIAC, triiodothyroacetic acid; $T_{3}$, triiodothyronine; $T_{4}$, thyroxine. 
Numerous studies over the past decade have established that glucocorticoids accelerate the synthesis and release of surfactant during fetal life (1). Corticosteroid effects in the lung are mediated by receptors and involve de novo protein synthesis (2). Administration of glucocorticoids to women in premature labor reduces the incidence of RDS in their premature infants. Treatment is not effective in every case, however. There is no benefit for infants exposed $<24 \mathrm{~h}$ to exogenous corticosteroids, and in some studies treatment has been relatively ineffective in male infants, even after optimal duration of treatment (3-5).

Several reports indicate that thyroid hormones also enhance lung maturation. Direct administration of thyroxine $\left(\mathrm{T}_{4}\right)$ to the fetal rabbit or maternal treatment with 3,5-dimethyl-3'isopropyl-L-thyronine (DIMIT) accelerates PC synthesis and morphologic development in the lung $(6,7)$, and increases the content of PC in lavage fluid (8). Recently, stimulation of PC synthesis by $T_{4}$ and triiodothyronine $\left(T_{3}\right)$ has been described for fetal rat $(9,10)$ and rabbit (2) lung in organ culture. However, there is little information relating to the mechanism of thyroid hormone action in fetal lung.

We have previously identified nuclear receptors for $T_{3}$ in lung of the fetal rabbit and human (11-13). This finding led us to propose that thyroid hormone effects in fetal lung were mediated through nuclear receptors. In the present study, we have characterized the effect of $T_{3}$ on PC synthesis in cultured fetal rabbit lung, and compared the results with $T_{3}$ binding. In addition, we describe effects of combined $T_{3}$ and glucocorticoid treatment of lung cultures. The results are discussed with regard to both the mechanism of $T_{3}$ action and the interaction of thyroid hormones and glucocorticoids.

\section{Methods}

Reagents. 3,5'-Diethyl-3'-isopropyl-DL-thyronine (DIET) was obtained from P. Block (Lot \#PB2254A-211). DIMIT used in these studies was received from the late E. Jorgensen (Lot \#MFM II-10-1). L-T 3 , other thyroid hormone analogs, and other biochemicals were purchased from Sigma Chemical Co., St. Louis, MO. For use in the culture system, thyroid hormones were dissolved in sterile $0.1 \mathrm{~N}$ sodium hydroxide. [Methyl $\left.-{ }^{3} \mathrm{H}\right]$ choline $(60 \mathrm{Ci} / \mathrm{mmol}),\left[6-{ }^{3} \mathrm{H}(\mathrm{N})\right] \mathrm{D}-$ glucose $(33 \mathrm{Ci} / \mathrm{mmol})$ $\left[1,2,3-{ }^{3} \mathrm{H}\right]$ glycerol $(200 \mathrm{mCi} / \mathrm{mmol}),\left[{ }^{3} \mathrm{H}\right]$ sodium acetate $(90 \mathrm{mCi} /$ $\mathrm{mmol})$, and $\left[{ }^{125} \mathrm{I}\right] \mathrm{T}_{3}(1.2 \mathrm{mCi} / \mu \mathrm{g})$ were obtained from New England Nuclear Co., Boston, MA.

Organ culture. Time-dated pregnant New Zealand White rabbits were used, with the day of conception designated day 0 of pregnancy. Lungs from 22-24 d gestation fetuses were placed in organ culture as previously described (2). In brief, fetuses were obtained by hysterotomy under pentobarbital anesthesia and the lungs were chopped into $\sim 1$ $\mathrm{mm}^{3}$ pieces. Tissue was distributed on a tissue culture dish and incubated in $2 \mathrm{ml}$ of Waymouth's MB-752/1 medium on a rocking platform. The tissue was cultured in the absence of serum with or without hormones for periods of generally 24-72 h. Incubations were carried out in an atmosphere of $95 \%$ oxygen and $5 \% \mathrm{CO}_{2}$, and fresh culture medium was added every $24 \mathrm{~h}$.

Phosphatidylcholine synthesis. The rate of choline incorporation into PC was determined after various periods of culture. The culture medium was removed and replaced with fresh Waymouth's medium containing $1 \mu \mathrm{Ci}\left[{ }^{3} \mathrm{H}\right] \mathrm{choline} / \mathrm{ml}$ (final specific activity, $0.56 \mathrm{Ci} / \mathrm{mol}$ ). After incubation for an additional $4 \mathrm{~h}$, the tissue was washed with cold isotonic saline and frozen overnight. The tissue was sonicated, lipids were extracted, and PC was isolated by thin layer chromatography as described (2). In some experiments, PC was extracted from the chromatography plate and reacted with osmium tetroxide; saturated and nonsaturated PC were separated according to the method described by Gross et al. (14). The tissue content of PC was determined by assay of phosphorus (15). In experiments using other radioactive precursors, cultures were incubated for $4 \mathrm{~h}$ in Dulbecca's modified essential H-21 medium containing glycerol, glucose, sodium acetate, and choline, all at $1 \mathrm{mM}$ concentration, plus tracer amounts of one radioactive compound. The distribution of radioactivity from $\left[{ }^{3} \mathrm{H}\right]$ acetate among tissue phospholipids was assessed by thin layer chromatography as described by Touchstone et al. (16).

DNA in the sonicate was assayed by fluorometry using diaminobenzoic acid (17). Statistical significance was assessed by paired or unpaired Student's $t$ test and by least squares linear regression. Data are expressed as mean $\pm \mathrm{SE}$.

\section{Results}

General properties. Choline was incorporated predominantly $(>95 \%)$ into PC by cultured lung. Saturated PC accounted for 20-24\% $(n=3)$ of newly synthesized PC in control cultures. The presence of $\mathrm{T}_{3}$, dexamethasone (Dex), or the combination of the two hormones did not affect the percent saturation of PC, in agreement with previous studies in this species $(2,18)$. Thus, data for hormonal stimulation applies to the rate of incorporation into both PC and saturated PC. Hormonal stimulation of choline incorporation into $\mathrm{PC}$ was associated with increased tissue content of PC, as previously observed $(2,19)$. The regression equation was PC content ( $\mu \mathrm{g}$ PC-Pi/ mg DNA) $=13.15+0.8309$ choline incorporation $(\mathrm{nmol} / 4$ $\mathrm{h} / \mathrm{mg}$ DNA) $(r=0.94, n=22)$ with lung cultured for $3 \mathrm{~d}$.

Table I summarizes all experiments examining stimulation

Table I. Stimulation of Choline Incorporation by $T_{3}$ and Dex in Fetal Lung of 22- to 24-d Gestation

\begin{tabular}{|c|c|c|c|c|}
\hline \multirow[b]{2}{*}{$\begin{array}{l}\text { Gestational } \\
\text { age }\end{array}$} & \multirow[b]{2}{*}{$n$} & \multicolumn{3}{|c|}{ Choline incorporation } \\
\hline & & $\mathrm{T}_{3}$ & Dex & $T_{3}+$ Dex \\
\hline & & \multicolumn{3}{|c|}{ \% stimulation vs. control } \\
\hline 22 & 2 & $11.9,0$ & $0,8.0$ & $17.2,30.6$ \\
\hline 23 & 22 & $50.0 \pm 5.8$ & $62.1 \pm 6.5$ & $161.4 \pm 11.4^{*}$ \\
\hline 24 & 5 & $65.2 \pm 23.2$ & $40.2 \pm 10.1$ & $93.8 \pm 20.7 \ddagger$ \\
\hline
\end{tabular}

Lung was cultured for $72 \mathrm{~h}$ ( $48 \mathrm{~h}$ for 22-d) in the absence of hormone (control) or with 2-5 nM T, $10-100 \mathrm{nM}$ Dex, or both hormones. The rate of choline incorporation into PC was determined as described in Methods; mean \pm SE values in control cultures for 22, 23 , and $24-d$ lung were 9.26 and $10.12,13.17 \pm 0.89$, and $21.89 \pm 1.80$ $\mathrm{nmol} / 4 \mathrm{~h} / \mathrm{mg}$ DNA, respectively.

* $\mathrm{P}<0.0001$ compared with $\mathrm{T}_{3}$ alone and Dex alone.

$\ddagger \mathrm{P}<0.05$ compared with $\mathrm{T}_{3}$ alone and Dex alone. 
of choline incorporation by $T_{3}$ in both the absence and presence of Dex. In two experiments with $22 \mathrm{~d}$ fetal lung, there was little effect of $T_{3}$ alone, and only a modest stimulation by $T_{3}$ plus Dex. $T_{3}$-stimulated incorporation to a similar extent in fetal lung of 23- and 24-d gestation cultured for $72 \mathrm{~h}$. The effect of $T_{3}$ plus Dex was greatest with 23-d lung, and was more than additive in 21 of the 22 experiments. The response to Dex alone was similar $(P=0.14)$ at 23 and $24 \mathrm{~d}$; however, the amount of stimulation with 24-d lung was less than previously observed. ${ }^{2}$ Further characterization of the hormonal response was carried out with $23-d$ lung.

We also tested the effect of $T_{3}$ and Dex on incorporation of other precursors of PC. Cultures of lung were exposed to these tritiated compounds at concentrations found to be optimal with isolated type II cells (20). As shown in Table II, both $T_{3}$ and Dex alone stimulated the incorporation of glucose, glycerol, and acetate into PC. The magnitude of the responses was less than observed with choline. Stimulation of incorporation rates by $T_{3}$ plus Dex was greater than with Dex alone in every experiment. The ratio of stimulation by $T_{3}$ plus Dex vs. the sum of stimulation by $T_{3}$ and Dex alone, as a measure of synergy, ranged between 0.83 and 2.11 for these compounds vs. a value of 1.44 for incorporation of choline (from Table I).

Table III presents data for the distribution of radioactivity from $\left[{ }^{3} \mathrm{H}\right]$ acetate among phospholipids of lung tissue. In control cultures, $74.1 \%$ of the total counts were present in PC, with $9 \%$ in both phosphatidylinositol and phosphatidylethanolamine; four other phospholipids each contained $<4 \%$ of the total radioactivity. Exposure of cultures to $T_{3}$ for $3 \mathrm{~d}$ did not affect the distribution of radioactivity. Treatment with Dex increased the percentage of radioactivity incorporated into PC (77.2\%) and reduced counts per minute in lyso PC and sphingomyelin. With $\mathrm{T}_{3}$ plus Dex, there was also more radioactivity in $\mathrm{PC}(80.3 \%)$ and less in all other phospholipids except for phosphatidylserine.

Time course. A representative experiment showing the time course of response to $T_{3}$, Dex, and both hormones is shown in Fig. 1. Lung from 23-d fetuses was cultured for 68 $h$ and exposed to hormone for the last $14,28,46$, or the entire $68 \mathrm{~h}$. The time courses for stimulation of choline incorporation by $T_{3}$ and Dex are similar. In other experiments (not shown), stimulation by $T_{3}$ was first detected between 8 and $12 \mathrm{~h}$ after addition of hormone. The response to $T_{3}$ plus Dex in this study was maximal by $44 \mathrm{~h}$, although in some experiments

2. The reason for the difference in responsiveness to Dex in this compared with our earlier study (2) is not known. The previous experiments were carried out in Oxford, England with local rabbits, while the present study used rabbits shipped by air to San Francisco from vendors in both Montana (involving a presumably stressful overnight layover) and Washington. The data at 24-d gestation were obtained early in the study with rabbits from Montana, which had a greater than expected occurrence of spontaneous abortion.
Table II. Effects of $T_{3}$ and Dex on Incorporation of Glucose, Glycerol, and Acetate into PC

\begin{tabular}{|c|c|c|c|c|}
\hline \multirow[b]{2}{*}{ Precursor } & \multicolumn{4}{|c|}{ Incorporation rate } \\
\hline & Control & $\mathrm{T}_{3}$ & Dex & $T_{3}+\operatorname{Dex}$ \\
\hline & $\begin{array}{l}\mathrm{nmol} / 4 \mathrm{~h} / \\
\mathrm{mg} D N A\end{array}$ & \multicolumn{3}{|c|}{ \% stimulation vs. control } \\
\hline Glucose & $6.14 \pm 0.70$ & $25.5 \pm 9.7$ & $8.3 \pm 6.1$ & $51.1 \pm 8.8^{*}$ \\
\hline Glycerol & $11.88 \pm 1.06$ & $8.1 \pm 5.5$ & $28.9 \pm 4.4$ & $78.0 \pm 7.9^{*}$ \\
\hline Acetate & $34.60 \pm 4.64$ & $28.9 \pm 6.5$ & $33.4 \pm 10.9$ & $51.4 \pm 10.6 \ddagger$ \\
\hline
\end{tabular}

Lung was cultured $72 \mathrm{~h}$ in the absence of hormone (control) or with $\mathrm{T}_{3}$ (2 $\mathrm{nM}$ ), Dex $(10 \mathrm{nM})$, or both hormones, and then exposed for $4 \mathrm{~h}$ to tritiated precursor. Mean $\pm S E$ values from three to five experiments are shown. $* P<0.03$ vs. Dex.

$\ddagger P=0.1$ vs. Dex.

stimulation continued to increase between 48 and $72 \mathrm{~h}$. The effect with $T_{3}$ plus Dex is greater than additive at the three later time points. After $28 \mathrm{~h}$ with both hormones, stimulation is greater than that achieved after $68 \mathrm{~h}$ with either Dex or $T_{3}$ alone.

We also examined hormonal response after shorter periods of culture. In five experiments, lung was cultured for $24 \mathrm{~h}$ in the absence or presence of hormones. Stimulation with $T_{3}(5$ $\mathrm{nM})$ was $11 \pm 7 \%$, and a response to Dex $(100 \mathrm{nM})$ was detected in only one experiment (12\%). With addition of $\mathrm{T}_{3}$ plus Dex, stimulation occurred in each experiment $(19.2 \pm 4.6 \%, P<0.05$ vs. Dex). After $48 \mathrm{~h}$ of culture $(n=6)$, the percent stimulation with $T_{3}$, Dex, and $T_{3}$ plus Dex was $30.7 \pm 5.1,37.0 \pm 7.5$, and $116.2 \pm 19.3 \%\left(P<0.01\right.$ vs. both Dex and $T_{3}$ alone), respectively.

In other studies, we examined the effect of removing $T_{3}$ during the incubation. In the experiments shown in Table IV, cultures were exposed to a low concentration of $T_{3}(0.2 \mathrm{nM})$

Table III. Distribution of Radioactivity from [3H] acetate among Phospholipids of Cultured Lung

\begin{tabular}{lllll}
\hline \multirow{5}{*}{ Phospholipid } & \multicolumn{4}{l}{ Distribution of radioactivity } \\
\cline { 2 - 5 } & Control & $\mathrm{T}_{3}$ & $\mathrm{Dex}$ & $\mathrm{T}_{3}+$ Dex \\
\hline & \% of total cpm & & \\
PC & $74.1 \pm 0.5$ & $75.5 \pm 0.5$ & $77.2 \pm 0.5^{*}$ & $80.3 \pm 0.2^{*}$ \\
Lysophosphatidylcholine & $1.0 \pm 0.02$ & $0.9 \pm 0.04$ & $0.8 \pm 0.06^{*}$ & $0.8 \pm 0.03^{*}$ \\
Sphingomyelin & $3.3 \pm 0.07$ & $3.4 \pm 0.04$ & $2.7 \pm 0.00^{*}$ & $2.6 \pm 0.07^{*}$ \\
Phosphatidylserine & $1.6 \pm 0.2$ & $1.5 \pm 0.06$ & $1.3 \pm 0.04$ & $1.3 \pm 0.1$ \\
Phosphatidylinositol & $9.0 \pm 0.3$ & $8.0 \pm 0.2$ & $8.2 \pm 0.3$ & $7.2 \pm 0.08^{*}$ \\
Phosphatidylethanolamine & $9.0 \pm 0.3$ & $8.5 \pm 0.2$ & $8.3 \pm 0.00$ & $6.5 \pm 0.2^{*}$ \\
Phosphatidylglycerol & $2.0 \pm 0.2$ & $2.1 \pm 0.02$ & $1.5 \pm 0.06$ & $1.3 \pm 0.00^{*}$
\end{tabular}

Lung was cultured for $3 \mathrm{~d}$ with $\mathrm{T}_{3}(2 \mathrm{nM})$, Dex (10 $\left.\mathrm{nM}\right)$, both hormones, or no additions (control), and then exposed to [3H]acetate for $4 \mathrm{~h}$. Phospholipids were extracted and chromatographed as described in Methods. Mean \pm SE values for triplicate determinations in a representative experiment are shown. $* P<0.05$ vs. control. 


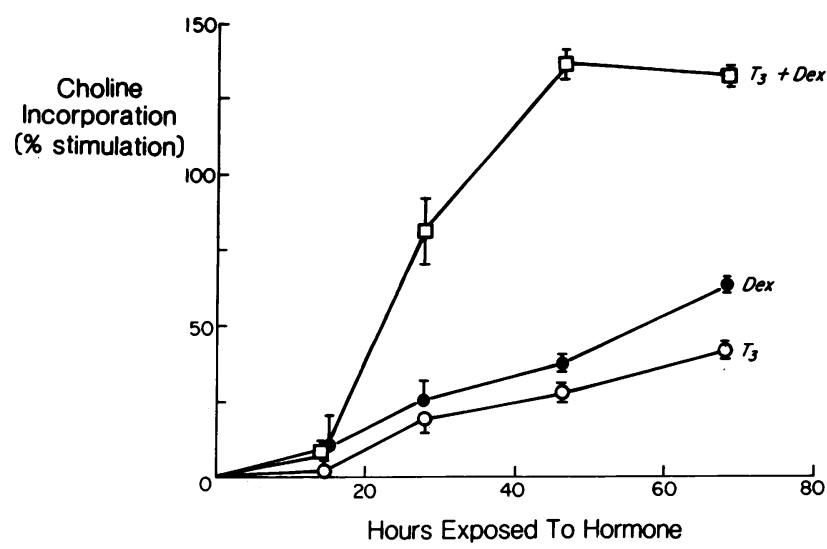

Figure 1. Time-course of hormonal stimulation. Lungs from 23-d rabbit fetuses were cultured for $68 \mathrm{~h}$ in the absence or presence of hormones. $T_{3}(1 \mathrm{nM})$, Dex $(10 \mathrm{nM})$, or $T_{3}$ plus Dex was added to the cultures for the entire $68 \mathrm{~h}$ or the last 46,28 , or $14 \mathrm{~h}$ of culture. The rate of choline incorporation was determined after $68 \mathrm{~h}$ of culture. Values are means $\pm \mathrm{SE}$ of triplicate determinations.

for 24 or $48 \mathrm{~h}$, in the absence (experiment 1) or presence (experiment 2) of Dex. The incubation was then continued in medium without $T_{3}$. Choline incorporation was determined at $72 \mathrm{~h}$ and compared with that in cultures continuously exposed to $T_{3}$. The removal of $T_{3}$ from nuclei of cultured tissue under these conditions was assessed using tracer amounts of $\left.{ }^{125} \mathrm{I}\right] \mathrm{T}_{3}$; counts per minute per milligram DNA decreased by $75 \% 24 \mathrm{~h}$ after the change of medium. The data in Table IV illustrate that the continued presence of $T_{3}$ is required for optimal stimulation, and that the hormonal effect is partially reversible within $24 \mathrm{~h}$. Results were similar in cultures exposed to $T_{3}$ alone or to $T_{3}$ in the presence of Dex.

To explore the interaction between $T_{3}$ and Dex, we examined the effect of sequential addition of the two hormones. Cultures were exposed to one hormone for $48 \mathrm{~h}$, and then received both hormones for the last $24 \mathrm{~h}$ of culture. There was greater stimulation of choline incorporation at $72 \mathrm{~h}$ when cultures were first exposed to Dex for $48 \mathrm{~h}$, with subsequent addition of $T_{3}$, than vice versa (Table $V$ ). The response to $T_{3}$ added during the last $24 \mathrm{~h}$ was greater in cultures pretreated with Dex (+8.53 nmol/4 h/mg DNA) than in those without prior treatment $(2.89 \mathrm{nmol})$. By contrast, prior exposure of tissue to $T_{3}$ did not increase the response to Dex. These findings indicate that exposure of cultured lung to Dex enhances the rate of response to $T_{3}$, but not vice versa.

Dose response. The effect of $\mathrm{T}_{3}$ concentration was studied in dose-response experiments such as shown in Fig. 2. Optimal response to $T_{3}$ occurred at concentrations $\geq 1 \mathrm{nM}$. Halfmaximal stimulation of choline incorporation occurred at a mean $\mathrm{T}_{3}$ concentration of $0.10 \mathrm{nM}$ (range, $0.05-0.2 \mathrm{nM}, n$ $=6$ ) in the absence of Dex and $0.13 \mathrm{nM}$ (range, $0.06-0.3 \mathrm{nM}$, $n=10$ ) in the presence of Dex. For comparison, the equilibrium dissociation constant $\left(K_{\mathrm{D}}\right)$ for $\mathrm{T}_{3}$ binding to receptor in nuclei isolated from fetal rabbit lung is $0.11 \pm 0.04 \mathrm{nM}$ (12).

Table IV. Effect of Washing $T_{3}$ Out of Cultures

\begin{tabular}{|c|c|c|}
\hline \multirow[b]{2}{*}{ Hormone exposure } & \multicolumn{2}{|l|}{ Choline incorporation } \\
\hline & (nmol/4 h/mg DNA) & (\% Stimulation by $\mathrm{T}_{3}$ ) \\
\hline \multicolumn{3}{|l|}{ Experiment 1: 48-h incubation } \\
\hline Dex & $10.5 \pm 0.28$ & - \\
\hline $\mathrm{T}_{3}+\mathrm{Dex}$ & $13.86 \pm 0.54^{*}$ & 32 \\
\hline \multicolumn{3}{|l|}{ 72-h incubation } \\
\hline Dex & $21.75 \pm 0.39$ & - \\
\hline$T_{3}+\operatorname{Dex}$ & $32.22 \pm 0.63^{*}$ & 48.1 \\
\hline$T_{3}+$ Dex for $24 \mathrm{~h}$, then Dex & $22.85 \pm 1.67 \ddagger$ & 5.1 \\
\hline$T_{3}+$ Dex for $48 \mathrm{~h}$, then Dex & $26.12 \pm 1.72 \ddagger$ & 20.1 \\
\hline \multicolumn{3}{|l|}{ Experiment 2: 72-h incubation } \\
\hline Control & 20.71 & - \\
\hline $\mathrm{T}_{3}$ & 30.06 & 45.1 \\
\hline $\mathrm{T}_{3}$ for $24 \mathrm{~h}$, then no hormone & 21.26 & 2.7 \\
\hline $\mathrm{T}_{3}$ for $48 \mathrm{~h}$, then no hormone & 23.95 & 15.6 \\
\hline
\end{tabular}

Cultures of 23-d lung were exposed to Dex $(10 \mathrm{nM})$ and $T_{3}(0.2 \mathrm{nM})$ as shown. After 24 and $48 \mathrm{~h}$, some cultures treated with $T_{3}$ were switched to $T_{3}$-free medium ( $T_{3}$ wash out). Choline incorporation was assayed after 48- or 72-h incubation. Data are mean $\pm S E$ values of triplicate determinations (experiment 1 ) or duplicate assays (experiment 2 ) which varied $<8 \%$. $* P<0.05$ compared with Dex alone at corresponding incubation period. $\ddagger P<0.05$ compared with $\mathrm{T}_{3}+\operatorname{Dex}(72 \mathrm{~h})$. 
Table V. Effect of Order of Hormone Addition

\begin{tabular}{|c|c|c|c|}
\hline \multicolumn{2}{|c|}{ Hormones present } & \multirow{2}{*}{$\begin{array}{l}\text { Stimulation } \\
\text { vs. no } \\
\text { hormones }\end{array}$} & \multirow{2}{*}{$\begin{array}{l}\text { Increase vs. } \\
\text { appropriate } \\
\text { control }\end{array}$} \\
\hline $0-48 \mathrm{~h}$ & $48-72 h$ & & \\
\hline & & $\%$ & $\begin{array}{l}n m o l / 4 h / m g \\
D N A\end{array}$ \\
\hline None & Dex & - & $6.8 \pm 1.79$ \\
\hline $\mathbf{T}_{3}$ & $T_{3}+\operatorname{Dex}$ & $97.9 \pm 12.4^{*}$ & $7.85 \pm 1.27$ \\
\hline None & $T_{3}$ & - & $2.89 \pm 0.24 \dagger$ \\
\hline Dex & $T_{3}+\operatorname{Dex}$ & $132 \pm 14.8^{*}$ & $8.53 \pm 1.34 \ddagger$ \\
\hline$T_{3}+\operatorname{Dex}$ & $T_{3}+\operatorname{Dex}$ & $177 \pm 24$ & - \\
\hline
\end{tabular}

Lung explants were exposed to Dex (10 nM) and/or $T_{3}(2 n M)$ for the periods shown and choline incorporation was assayed after $72 \mathrm{~h}$ of culture. Percent stimulation is compared with cultures in the absence of hormones $(n=6)$. In three of the experiments, the increase in rate of choline incorporation resulting from addition of $T_{3}$ or Dex at $48 \mathrm{~h}$ was determined (e.g., the control system for $T_{3}(0-48 \mathrm{~h})$ then $\mathrm{T}_{3}+$ Dex (48-72 h), on line 2, was $T_{3}$ for all $72 \mathrm{~h}$ ).

$* P<0.01$.

$\ddagger P<0.05$.

Similar dose-response studies were carried out for seven other thyroid hormones. We tested the effect of $D-T_{3}, L-T_{4}$, $\mathrm{T}_{3}$-proprionic acid, triiodothyroacetic acid (TRIAC), $\mathrm{rT}_{3}$, and two synthetic noniodinated analogs (D,L-DIET, and L-DIMIT). In initial experiments we examined stimulation of choline incorporation at a relatively high dose of each hormone $(\sim 15$ fold greater than the $K_{\mathrm{D}}$ for nuclear binding) (12). Each compound stimulated choline incorporation to a similar extent in both the absence and presence of Dex (Table VI). The results from dose-response studies are summarized in Fig. 3. The concentration of each hormone required for half-maximal

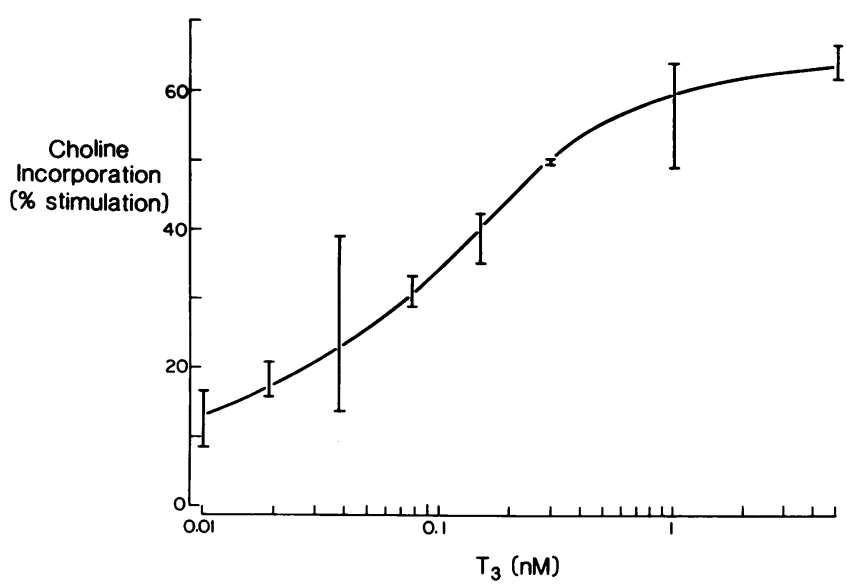

Figure 2. $\mathrm{T}_{3}$ dose response. Fetal lung was cultured for $72 \mathrm{~h}$ in the presence of various concentrations of $T_{3}$ as shown. The range of duplicate determinations are shown.
Table VI. Stimulation of Choline Incorporation by Iodothyronines and Noniodinated Analogs

\begin{tabular}{lcll}
\hline & & \multicolumn{2}{l}{$\begin{array}{l}\text { Percent stimulation of } \\
\text { choline incorporation }\end{array}$} \\
\cline { 3 - 4 } Analog & Concentration & No Dex & $\begin{array}{l}\text { In presence } \\
\text { of Dex }\end{array}$ \\
\hline & $n M$ & & \\
L-T $_{3}$ & 2.0 & 45.9 & 74.4 \\
D-T $_{3}$ & 2.0 & 48.2 & 55.5 \\
TRIAC $_{\text {T }}$ & 0.77 & 39.2 & 63.1 \\
L-Troprionic acid $_{4}$ & 1.34 & 51.9 & 46.7 \\
DIET & 22 & 43.7 & 57.7 \\
DIMIT & 63 & 50.2 & 50.2 \\
rT & & 40.4 & 57.3 \\
& 103 & 60.5 & 40.3 \\
& 89 & &
\end{tabular}

Cultures of 23-d fetal lung were exposed to thyroid hormone for $72 \mathrm{~h}$ in either the absence of Dex (no Dex) or in the presence of $10 \mathrm{nM}$ Dex; choline incorporation was compared with that in cultures containing no hormones or Dex alone, respectively. Data are mean values of duplicate determinations which varied $<9 \%$.

stimulation of choline incorporation is plotted vs. the $K_{\mathrm{D}}$ value for receptor binding (12). Both $\mathrm{T}_{3}$-proprionic acid and TRIAC were more potent than $L-T_{3}$, and these analogs also have lower $K_{\mathrm{D}}$ values than $\mathrm{T}_{3}$ for receptor binding. $\mathrm{L}-$ and $\mathrm{D}-\mathrm{T}_{3}$ were similar in both potency and affinity. The potency of $\mathrm{L}_{-} \mathrm{T}_{4}$ was $8.8 \%$ of that for $\mathrm{L}_{-} \mathrm{T}_{3}, \mathrm{rT}_{3}$ and the synthetic analogs demonstrated potencies between 1 and $2 \%$ of that for $T_{3}$. The values for the eight thyroid hormones are grouped around the line of

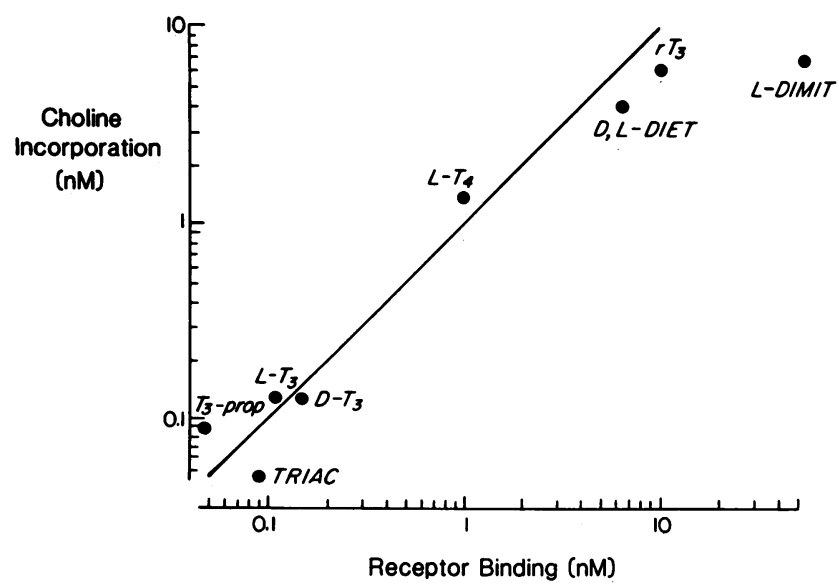

Figure 3. Comparison of potency and binding affinity for various thyroid hormones. Dose-response experiments for stimulation of choline incorporation were carried out with each hormone. Mean values for half-maximal stimulation from two or three experiments are plotted vs. the $K_{\mathrm{D}}$ for binding to receptor in isolated fetal rabbit lung nuclei (12). The line of identity is shown. 
identity indicating a close correlation between potency and binding affinity.

Requirement for RNA and protein synthesis. The requirement for RNA synthesis in the $T_{3}$ response was investigated using actinomycin D. As shown in Fig. 4, the presence of actinomycin $D$ decreased the $T_{3}$ effect in a dose-dependent fashion, and abolished stimulation at a dose of $0.2 \mu \mathrm{g} / \mathrm{ml}$. The response to $T_{3}$ plus Dex in this and two other experiments was decreased but not eliminated by $0.2 \mu \mathrm{g} / \mathrm{ml}$ actinomycin D. In these experiments, cultures were exposed to hormone with or without inhibitor for the last $48 \mathrm{~h}$ of the 72-h culture period. This approach reduced the depression of choline incorporation in control cultures receiving actinomycin $D$. In four experiments of this design, stimulation by $T_{3}$ was $24.4 \pm 3.8 \%$ compared with $2.1 \pm 2.1 \%(P<0.01)$ in the presence of actinomycin $D(0.2 \mu \mathrm{g} / \mathrm{ml})$. In three other experiments, actinomycin $D$ was added only during the last $24 \mathrm{~h}$ of culturing; stimulation by $\mathrm{T}_{3}$ was $36.0 \pm 10.5$ vs. $18.9 \pm 6.2 \%$ (NS) in the absence and presence of inhibitor, respectively.

The requirement for protein synthesis was studied using cycloheximide. Control and hormone-treated cultures were exposed to cycloheximide $(0.4 \mu \mathrm{g} / \mathrm{ml})$ during the last $24 \mathrm{~h}$ of a 72-h incubation. As illustrated by the data shown in Table VII, this treatment caused only a slight reduction in choline incorporation by control cultures, but eliminated the stimulation by $T_{3}$. Cycloheximide was equally effective whether present during the entire time of hormone treatment $(48 \mathrm{~h})$ or when added only during the last $24 \mathrm{~h}$ of culture (data not shown). The response to Dex alone and to $T_{3}$ plus Dex was somewhat less sensitive to cycloheximide treatment than for $T_{3}$ (Table VII).

\section{Discussion}

Previous studies with cultured lung indicated direct effects of thyroid hormone in this tissue $(9,10,21-23)$; however, there

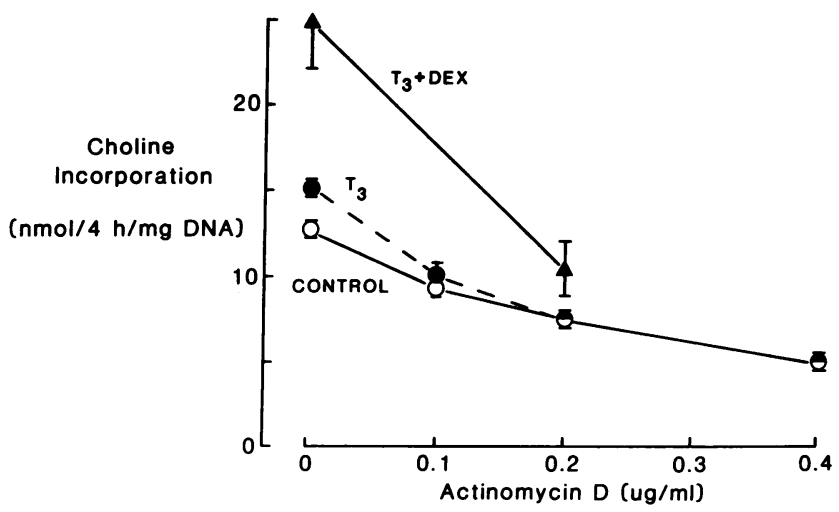

Figure 4. Inhibition of hormonal stimulation by various doses of actinomycin D. Choline incorporation was assayed after culture of fetal lung for $72 \mathrm{~h}$. $\mathrm{T}_{3}(1 \mathrm{nM})$ and $\mathrm{T}_{3}$ plus Dex $(100 \mathrm{nM})$ alone or with various concentrations of actinomycin $D$ were present for the last $46 \mathrm{~h}$ of culture. Mean \pm SE values of triplicate determinations are shown.
Table VII. Effect of Cycloheximide on

Hormonal Stimulation of Choline Incorporation

\begin{tabular}{llc}
\hline & \multicolumn{2}{l}{ Choline incorporation } \\
\cline { 2 - 3 } Addition & No inhibitor & Cycloheximide \\
\hline & $n m o l / 4 h / m g ~ D N A$ & \\
None & 9.84 & 8.46 \\
$T_{3}$ & 13.45 & 8.78 \\
Dex & 17.09 & 11.19 \\
$T_{3}+$ Dex & 23.97 & 17.27
\end{tabular}

Lung was cultured $72 \mathrm{~h}$ without hormone or with $\mathrm{T}_{3}(1 \mathrm{nM})$, Dex $(10 \mathrm{nM})$, or both hormones. Cycloheximide $(0.04 \mu \mathrm{g} / \mathrm{ml})$ or diluent (no inhibitor) was added during the last $24 \mathrm{~h}$ of culture before determination of choline incorporation. Data are mean values of duplicate assays which varied $<10 \%$.

is little information relating to the mechanism of action. Based on the identification of nuclear $T_{3}$ receptors in fetal lung (11-13), we postulated that $T_{3}$ stimulation of $P C$ synthesis was mediated through receptor. Our findings support this mechanism of action. The response to $T_{3}$ has a lag phase, and stimulation continues for $48-72 \mathrm{~h}$; this pattern is similar to the response in cultured hepatocytes $(24)$ and is consistent with new synthesis of macromolecules. Continued stimulation of PC synthesis requires the continued presence of $T_{3}$ during culture, consistent with a reversible binding reaction. Halfmaximal stimulation occurs at the same concentration of $T_{3}$ $(0.1 \mathrm{nM})$ which produces half-maximal saturation of nuclear receptors (12), indicating a linear relationship between occupancy of receptors and response in lung. A similar relationship has been described for $T_{3}$ effects on both enzyme induction in cultured hepatocytes (25) and synthesis of growth hormone in $\mathrm{GH}_{1}$ cells (26). With cultured rat lung, higher concentrations of $\mathrm{T}_{3}(\sim 2.5 \mathrm{nM})$ were required for half-maximal stimulation of choline incorporation (10). We found a close correlation between potency and binding affinity for seven other thyroid hormones in rabbit lung, providing perhaps the strongest evidence for receptor mediation.

The inhibition of the $T_{3}$ effect by actinomycin $D$ and cycloheximide is consistent with de novo synthesis of specific mRNA and protein. Glucocorticoid stimulation of PC synthesis is also blocked by these compounds (2). The rapid reversibility of the $T_{3}$ effect by both cycloheximide and hormone removal could indicate that the induced protein(s) has a relatively short half-life (i.e., $\leq 6 \mathrm{~h}$ ). It is of interest that the presence of actinomycin $D$ during the last $24 \mathrm{~h}$ of culture with $\mathrm{T}_{3}$ did not completely block stimulation, whereas the continuous presence of inhibitor at the same concentration eliminated the $T_{3}$ effect. This might indicate that the half-life of mRNA induced by $T_{3}$ is longer than for the induced protein. Stimulation by Dex alone and by Dex plus $T_{3}$ was less sensitive to cycloheximide than for $T_{3}$, suggesting that glucocorticoids induce different proteins involved in phospholipid synthesis, with a longer halflife than occurs with $T_{3}$. 
Our findings are consistent with a mechanism of $T_{3}$ action involving in part de novo induction of enzyme(s) related either directly (choline incorporation pathway) or indirectly (production of substrates or cofactors) to PC synthesis. However, there is relatively little information regarding the possible identity of induced protein(s). DIMIT treatment in the rabbit stimulates choline incorporation by fetal lung under conditions where the activity of phosphatidic acid phosphatase, a glucocorticoid inducible enzyme, is not increased (8). Both thyroid hormones and glucocorticoids increase the activity of cholinephosphate cytidylyltransferase, apparently by increasing the concentration of a phospholipid cofactor (27). The intracellular concentration of choline and other precursors was not determined in this study; accordingly, we cannot rule out an effect of $T_{3}$, mediated by receptor, on substrate pool size.

Our data confirm and further characterize the interaction between thyroid hormones and glucocorticoids in fetal lung. There is an additive effect of $T_{3}$ and Dex on choline incorporation after in vivo treatment of the fetal rat (27), and a synergistic interaction for combined treatment in both organ (10) and monolayer (21) cultures of rat lung. A synergistic and/or permissive interaction between thyroid hormones and glucocorticoids also occurs in other biological systems (2831). We found that the presence of both hormones gave more than additive stimulation of choline incorporation under all conditions examined. These included culturing tissue for $72 \mathrm{~h}$ and exposing the cultures to hormones for various times before assay, as well as determining the response during shorter periods of culture (i.e., less mature lung). Hormonal stimulation with other precursors was additive (acetate) or supra-additive (glucose and glycerol), supporting the findings with choline. The concentration of $T_{3}$ producing half-maximal response was identical in the presence and absence of Dex. This would appear to rule out a glucocorticoid-induced change in lung sensitivity to $T_{3}$ (receptor affinity) as the mechanism for synergy.

Although the time course of response and percent stimulation were similar for $T_{3}$ and Dex, differences in the action of the two hormones were observed. $T_{3}$ did not influence the distribution of radioactivity from acetate, whereas Dex increased incorporation into PC at the expense of other phospholipids. Stimulation by $T_{3}$ was more sensitive to actinomycin $D$ and cycloheximide. Prior exposure of cultures to Dex increased the rate of response to $T_{3}$ whereas the reverse situation was not observed. These results support previous indications (8-10) that thyroid hormones and glucocorticoids act, at least in part, at different biochemical sites in the synthesis of PC. This conclusion is consistent with supra-additive stimulation. One possibility might be the induction of phosphatidic acid phosphatase by corticosteroids and induction of enzyme(s) involved in fatty acid synthesis by $T_{3}$. These considerations also suggest that the two hormones do not act entirely through a common mediator, such as cAMP (21), to enhance PC biosynthesis. Glucocorticoids, but not thyroid hormones, increase $\beta$-adrenergic receptors in fetal lung $(32,33)$, indicating that the two hormones also differ in their effect on a protein not directly involved in surfactant synthesis.

Endogenous thyroid hormones appear to influence the normal process of lung maturation. In fetal sheep, thyroidectomy lowered lecithin/sphingomyelin values in tracheal fluid and delayed morphologic development (34). In rabbit lung, the number of nuclear receptor sites occupied by endogenous thyroid hormone increases about threefold between days 23 and 28 of gestation (12). Our observation that physiologic concentrations of $T_{3}$ stimulate $P C$ synthesis supports the possible role of endogenous $T_{3}$ and $T_{4}$.

These data, along with previous information $(2,6-10,22$, 35 ) and preliminary data with human fetal lung in culture (36), support the possibility that thyroid hormone treatment may benefit premature infants at risk for RDS. Although prenatal glucocorticoid therapy reduces the incidence of RDS, this treatment is not always effective. Potentially, combined antenatal therapy with thyroid hormone and glucocorticoid could be more efficacious than corticosteroid alone.

\section{Acknowledgments}

We thank P. Block for providing DIET, T. M. Chou and R. Ertsey for technical assistance, and M. Biagini and C. Dahlstrom for preparing the manuscript.

This research was supported by grants from the National Institutes of Health nos. HL-24075, HL-24056, HL/HD-30541, and HL-29564.

\section{References}

1. Ballard, P. L. 1982. Hormonal aspects of fetal lung development. In Development of the Lung and the Pathobiology of Hyaline Membrane Disease. P. M. Farrell, editor. Academic Press, Inc., New York. 205-253.

2. Gross, I., P. L. Ballard, R. A. Ballard, C. T. Jones, and C. M. Wilson. 1983. Corticosteroid stimulation of phosphatidylcholine synthesis in cultured fetal rabbit lung: evidence for de novo protein synthesis mediated by glucocorticoid receptors. Endocrinology. 112:829837.

3. Ballard, P. L., R. A. Ballard, J. P. Granberg, S. Sniderman, P. D. Gluckman, S. L. Kaplan, and M. M. Grumbach. 1980. Fetal sex and prenatal betamethasone therapy. J. Pediatr. 97:451-454.

4. Papageorgiou, A. N., E. Colle, E. Farri-Kostopoulos, and M. M. Gelfand. 1981. Incidence of respiratory distress syndrome following antenatal betamethasone: role of sex, type of delivery, and prolonged rupture of membranes. Pediatrics. 67:614-617.

5. Collaborative Group on Antenatal Steroid Therapy. 1981. Effect of antenatal dexamethasone administration on the prevention of respiratory distress syndrome. Am. J. Obstet. Gynecol. 141:276-286.

6. Hitchcock, K. R. 1979. Hormones and the lung. I. Thyroid hormones and glucocorticoids in lung development. Anat. Rec. 194:1540.

7. Wu, B., Y. Kikkawa, M. M. Orzalesi, E. K. Motoyama, M. Kaibara, C. J. Zigas, and C. D. Cook. 1973. The effect of thyroxine on the maturation of fetal rabbit lungs. Biol. Neonate. 22:161-168.

8. Ballard, P. L., B. J. Benson, A. Brehier, and J. P. Carter. 1980. Transplacental stimulation of lung development in the fetal rabbit by 3,5-dimethyl-3'-isopropyl-L-thyronine. J. Clin. Invest. 65:1407-1417. 
9. Gross, I., C. M. Wilson, L. D. Ingleson, A. Brehier, and S. A. Rooney. 1980. Fetal lung in organ culture. III. Comparison of dexamethasone, thyroxine and methylxanthines. J. Appl. Physiol. 48:872877.

10. Gross, I., and C. M. Wilson. 1982. Fetal lung in organ culture. IV. Supra-additive hormone interactions. J. Appl. Physiol. 54:14201425.

11. Lindenberg, J. A., A. Brehier, and P. L. Ballard. 1978. Triiodothyronine nuclear binding in fetal and adult rabbit lung and cultured lung cells. Endocrinology. 103:1725-1731.

12. Gonzales, L. W., and P. L. Ballard. 1982. Nuclear 3,5,3'triiodothyronine receptors in rabbit lung: characterization and developmental changes. Endocrinology. 111:542-552.

13. Gonzales, L. W., and P. L. Ballard. 1981. Identification and characterization of nuclear $\mathrm{T}_{3}$-binding sites in fetal human lung. $J$. Clin. Endocrinol. Metab. 53:21-28.

14. Gross, I., C. M. Wilson, L. D. Ingleson, A. Brehier, and S. A. Rooney. 1979. The influence of hormones on the biochemical development of fetal rat lung in culture. I. Estrogen. Biochim. Biophys. Acta. 575:375-383.

15. Bartlett, G. R. 1959. Phosphorus assay in column chromatography. J. Biol. Chem. 234:466-468.

16. Touchstone, J. C., J. C. Chen, and K. M. Beaver. 1980. Improved separation of phospholipids in thin layer chromatography. Lipids. 15:61-62.

17. Setaro, F., and C. G. D. Morley. 1976. A modified fluorimetric method for the determination of microgram quantities of DNA from cell or tissue culture. Anal. Biochem. 71:313-320.

18. Rooney, S. A., L. I. Gobran, P. A. Marino, W. M. Maniscalco, and I. Gross. 1979. Effects of betamethasone on phospholipid content, composition and biosynthesis in fetal rabbit lung. Biochim. Biophys. Acta. 572:64-76.

19. Mendelson, C. R., J. M. Johnston, P. C. MacDonald, and J. M. Snyder. 1981. Multihormonal regulation of surfactant synthesis by human fetal lung in utero. J. Clin. Endocrin. Metab. 53:307-317.

20. Batenberg, J. J., W. J. Longmore, and L. M. G. Van Golde. 1978. The synthesis of phosphatidylcholine by adult rat lung alveolar type II cells in primary culture. Biochim. Biophys. Acta. 529:160-170.

21. Smith, B. T., and K. Sabry. 1983. Glucocorticoid-thyroid synergism in lung maturation: a mechanism involving epithelialmesenchymal interaction. Proc. Natl. Acad. Sci. USA. 80:1951-1954.

22. Smith, B. T., and J. S. Torday. 1974. Factors affecting lecithin synthesis by fetal lung cells in culture. Pediatr. Res. 8:848-851.

23. Longmuir, K. J., J. E. Bleasdale, J. G. Quirk, and J. M. Johnston. 1982. Regulation of lamellar body acidic glycerophospholipid biosynthesis in fetal rabbit lung in organ culture. Biochim. Biophys. Acta. 712:356-364.

24. Ismail-Beigi, F., D. M. Bissell, and I. S. Edelman. 1979. Thyroid thermogenesis in adult rat hepatocytes in primary monolayer culture. J. Gen. Physiol. 73:369-381.

25. Mariash, C. N., and J. H. Oppenheimer. 1983. Interrelationship of triiodothyronine concentration, metabolism, protein binding, and nuclear occupancy in the induction of malic enzyme by cultured adult rat hepatocytes. Endocrinology. 112:80-85.

26. Samuels, H. H., F. Stanley, and L. E. Shapiro. 1976. Dosedependent depletion of nuclear receptors by L-triiodothyronine: evidence for a role in induction of growth hormone synthesis in cultured $\mathbf{G H}_{1}$ cells. Proc. Natl. Acad. Sci. USA. 11:3877-3880.

27. Gross, I., D. W. Dynia, C. M. Wilson, L. D. Ingleson, I. H. Gewolb, and S. A. Rooney. 1983. Glucocorticoid-thyroid hormone interactions in fetal rat lung. Pediatr. Res. 18:191-196.

28. Evans, R. M., N. C. Birnberg, and M. G. Rosenfeld. 1982 Glucocorticoid and thyroid hormones transcriptionally regulate growth hormone gene expression. Proc. Natl. Acad. Sci. USA. 79:7659-7663.

29. Kriz, B. M., J. A. Gaites, S. E. Reed, and B. B. Fong. 1982 Synergistic regulation of fetal rat liver nicotinamide adenine dinucleotide phosphate (reduced form) cytochrome C-reductase activity: effects of L-triiodothyronine and hydrocortisone. Endocrinology. 110:2145-2150.

30. Spence, J. T., and H. C. Pitot. 1979. Hormonal regulation of glucokinase in primary cultures of adult rat hepatocytes. J. Biol. Chem. 254:12331-12336.

31. Motwani, N. M., N. J. Unakar, and A. K. Roy. 1980. Multiple hormone requirement for the synthesis of $\alpha_{2 u}$-globulin by monolayers of rat hepatocytes in longterm primary culture. Endocrinology. 107:1606-1613.

32. Cheng, J. B., A. Goldfien, P. L. Ballard, and J. M. Roberts. 1980. Glucocorticoids increase pulmonary $\beta$-adrenergic receptors in fetal rabbit. Endocrinology. 107:1646-1651.

33. Giannopoulos, G., and S. K. Sommers-Smith. 1982. Hormonal regulation of $\beta$-adrenergic receptors in fetal rabbit lung in organ culture. Life Sci. 31:795-802.

34. Erenberg, A., M. L. Rhodes, M. M. Weinstein, and R. L. Kennedy. 1979. The effect of fetal thyroidectomy on ovine fetal lung maturation. Pediatr. Res. 13:230-235.

35. Mashiach, S., G. Barkai, J. Sack, E. Stern, M. Brish, B. Goldman, and D. M. Serr. 1979. The effect of intra-amniotic thyroxine administration on fetal lung maturity in man. J. Perinat. Med. 7:161170.

36. Ballard, P. L., and L. K. Gonzales. 1984. Hormonal stimulation of phosphatidylcholine synthesis in cultured human fetal lung. Clin. Res. 32:120A. (abstr.) 